\title{
cmaJOPEN
}

\section{Structures, processes and models of care for emergency general surgery in Ontario: a cross-sectional survey}

\author{
Graham Skelhorne-Gross MD PhD, Rahima Nenshi MD MSc, Angela Jerath MD MSc, David Gomez MD PhD
}

Abstract

Background: Emergency general surgery (EGS) patients require urgent surgical evaluation and intervention for various conditions, such as infectious or obstructive diseases of the gastrointestinal tract. We aimed to characterize the structures and processes that are relevant to the delivery of EGS care across Ontario hospitals and to evaluate the availability of critical resources at hospitals with formal EGS models.

Methods: Between August 2019 and July 2020, we conducted a cross-sectional survey of Ontario hospitals that offered urgent general surgery (defined as the ability to provide nonelective surgical intervention within 24 to 48 hours of presentation) to adults. People with intimate knowledge of their hospital's EGS program completed a Web-based or telephone survey characterizing the program's organizational structure and staffing, operating room availability, interventional radiology and interventional endoscopy availability, intensive care unit availability and staffing, and regional participation. Their responses were compiled and comparisons were made between hospitals with and without formal EGS models of care, as well as between hospitals based on size and academic status.

Results: Of the 114 Ontario hospitals identified, 109 responded (95.6\% response rate). A third (34.6\%; $n=37 / 107)$ of hospitals had EGS models of care. Thirty-four of these $(91.9 \%)$ were large (> 100-bed) institutions that would be likely to have increased resources. However, even for hospitals of similar size, those with EGS models had increased staffing levels compared to those without (clinical associates $17.6 \%$ [ $n=3 / 17]$ v. $10.0 \%$ [ $n=2 / 20]$; nurse practitioners or physician assistants $27.8 \%[n=5 / 18]$ v. $14.3 \%[n=3 / 21]$ ). They also had better access to diagnostic and interventional equipment (24/7 access to computed tomography 94.1\% [ $n=16 / 17]$ v. $69.2 \%[n=18 / 26])$, interventional radiology $(88.9 \%[n=16 / 18]$ v. $42.3 \%[n=11 / 26])$, endoscopy $(100 \%[n=18 / 18]$ v. $69.2 \%[n=$ $18 / 26])$ and endoscopic retrograde cholangiopancreatography $(77.8 \%[n=14 / 18]$ v. $42.3 \%[n=11 / 26])$, as well as dedicated operating room time $(72.2 \%[n=13 / 18]$ v. $0 \%[n=0 / 25])$.

Interpretation: The structures and processes available to care for patients requiring EGS in Ontario were highly variable between hospitals. Hospitals with formal EGS models were more likely to have access to key resources.

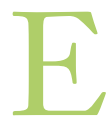

mergency general surgery (EGS) is a subdivision of general surgery focused on the care of patients who require urgent surgical evaluation and treatment. EGS patients present with a wide variety of conditions, including infectious diseases, hemorrhagic conditions and obstructive diseases of the gastrointestinal tract. ${ }^{1}$ Presentations needing EGS are common - exceeding the incidence of newly diagnosed cancer and diabetes - and represent $7.1 \%$ of hospital admissions. ${ }^{2}$ These presentations can be quite complex. Many EGS patients have severe physiologic derangements (i.e., hypovolemia from sepsis, dehydration and bleeding) that require optimization before definitive management. ${ }^{3}$ Not surprisingly, the mortality rate in patients requiring EGS is 8 times higher than in nonemergent surgical patients, and the complication rate is 1.5 times higher. ${ }^{4,5}$ EGS patients undergo only $11 \%$ of general surgery operations but experience $28 \%$ of complications and $47 \%$ of deaths. ${ }^{6-10}$ Best-practice pathways and dedicated multidisciplinary teams exist for other patients who need acute complex surgery, such as trauma patients. However, care for EGS patients has not been standardized and often falls under the purview of on-call general surgeons, who have varying experience and access to hospital resources (i.e., operating room, intensive care unit) depending on their location. ${ }^{11}$

An EGS model of care is an organizational structure that provides protected time for surgeons to focus on the care of patients with surgical emergencies, as well as specific

\section{Competing interests: None declared.}

This article has been peer reviewed.

Correspondence to: David Gomez, gomezda@smh.ca CMAJ Open 2021 November 23. DOI:10.9778/cmajo.20200306 
structures and processes designed to improve the care of patients with general surgical emergencies. ${ }^{12}$ This includes staffing resources, access to diagnostic and interventional services (e.g., endoscopy, radiology), dedicated operating room time, access to intensive care units and interhospital agreements to transfer high-risk patients. ${ }^{12}$

In 2009, 13 Canadian hospitals had EGS models of care. ${ }^{1}$ In the decade since, evidence has accumulated suggesting that EGS models improve patient outcomes by decreasing postoperative complications and mortality.,11-13 EGS models of care decrease the time to surgical review, ${ }^{13,14}$ increase the proportion of cases performed during daylight hours and decrease length of hospital stay. ${ }^{15-22}$ Collectively, these models of care substantially decrease the cost of managing EGS conditions. ${ }^{12,19}$ However, despite these benefits, the structures and processes that are relevant to the delivery of EGS care are highly variable among institutions and have never been formally assessed in Canada. In this study, we characterized these structures and processes across all hospitals that provide urgent surgical care in Ontario. We also evaluated whether the presence of an EGS model of care was associated with increased availability of critical resources, independent of hospital size.

\section{Methods}

\section{Study design}

This study was a cross-sectional survey of leaders and directors of general surgery across all hospitals that provide urgent surgical care in Ontario. We defined urgent surgical care as the ability to provide nonelective surgical intervention within 24 to 48 hours of presentation (for example, the ability to provide surgical care for acute appendicitis or cholecystitis). Responses were collected between August 2019 and July 2020.

\section{Hospital and survey recipient selection}

We accessed a complete list of Ontario's hospitals from the Ministry of Health $(\mathrm{MOH})$ website, ${ }^{23}$ which classified 151 hospitals in categories based on the type of care they provided as per Regulation 964. ${ }^{24}$ We considered Group A (large $>100$-bed academic hospitals), Group B (large > 100-bed nonacademic hospitals), and Group C (small < 100-bed nonacademic hospitals) hospitals for inclusion in our survey. The $\mathrm{MOH}$ defines academic hospitals as those with formal agreements to provide instruction to medical students, residents and fellows. ${ }^{23}$ Practically, this means that medical learners contribute substantially to the care of patients at these academic institutions. Hospitals classified as Groups D through $\mathrm{V}$ (psychiatric, rehabilitation, chronic and continuing care facilities, etc.) do not provide acute treatment to patients requiring EGS.

We used official hospital websites and phone calls to administrative personnel to determine whether each hospital offered urgent general surgery services. All Ontario hospitals that offered urgent or emergent adult general surgery were included in the study. We targeted individual recipients who possessed intimate knowledge of the structures and processes of that hospital's surgical service. In order of highest to lowest preference, we contacted the chief of emergency general surgery, the chair of general surgery, a general surgeon who participated in the EGS on-call schedule, the chief of surgery, the chief of staff or the director of perioperative services. Each respondent was asked to confirm that they were familiar with the resources at their institution that were relevant to the care of EGS patients.

\section{Survey design}

The survey was designed to address 5 core components of EGS models of care based on a review we conducted of the relevant literature: organizational structure and staffing, operating room availability, interventional radiology and interventional endoscopy availability, intensive care unit availability and staffing, and regional participation. , $^{71,12,18-22,25-28} \mathrm{We}$ conducted the literature review in PubMed (National Library of Medicine) using the search criteria "emergency general surgery" and "models," as well as "outcomes." We refined the search with parameters specific to the last 10 years and publications including systematic reviews, meta-analyses, randomized controlled trials, reviews and clinical trials. Wherever possible, the source document was referenced.

We developed the survey to address each of these domains, which have been shown to affect outcomes for patients requiring EGS. Most questions required yes or no answers. We included 1 multiple choice question, and some (such as those addressing how much dedicated operating room time was available or access to interventional radiology, interventional endoscopy or endoscopic retrograde cholangiopancreatography or interventional radiology) were answered in free-text format (Appendix 1, available at www.cmajopen.ca/content/9/4/E1026/suppl/DC1). Before implementation, we pilot-tested a draft survey with 2 EGS surgeons who were not potential respondents, and we modified the survey based on their feedback. We collected answers using SurveyMonkey (surveymonkey.com); we did not use an electronic completeness check.

\section{Survey implementation}

We contacted all participants via email for the first round of the survey. A cover letter outlining the objectives of the survey, the time commitment and an opportunity to opt out accompanied the first-round email. We sent reminder emails after 3 and 7 weeks, as per the Dillman total design survey method. ${ }^{29}$ Given that the aim was to have a near $100 \%$ response rate, we conducted a fourth and last round, which consisted of phone interviews.

\section{Statistical analysis}

We analyzed all responses together, and then stratified hospitals by academic status, the presence of EGS models of care and number of beds. Some respondents did not answer some questions, so denominators varied slightly within groups depending on the question. We described categorical variables using frequency and proportion. We summarized continuous variables using median and interquartile range (IQR). We compiled and analyzed the survey data using GraphPad Prism 8.3.0 software. 


\section{Ethics approval}

The study was reviewed and approved by the research ethics board at St. Michael's Hospital, Toronto.

\section{Results}

We contacted each of the 151 Ontario hospitals identified by the $\mathrm{MOH}$ as being in Group A, B or C. We excluded 37 hospitals because 33 provided no adult urgent or EGS services, 1 provided only pediatric services, and 3 had amalgamated and no longer existed as stand-alone institutions. The remaining 114 hospitals received the survey, and 109 (95.6\%) responded (Figure 1). Of the respondents, 64.6\% $(n=42 / 65)$ from large hospitals were chiefs of surgery, general surgery division chairs or general surgeons who participated in the on-call schedule; most respondents from small hospitals $(90.9 \% ; n=40 / 44)$ were chiefs of staff or managers of perioperative services (Table 1).

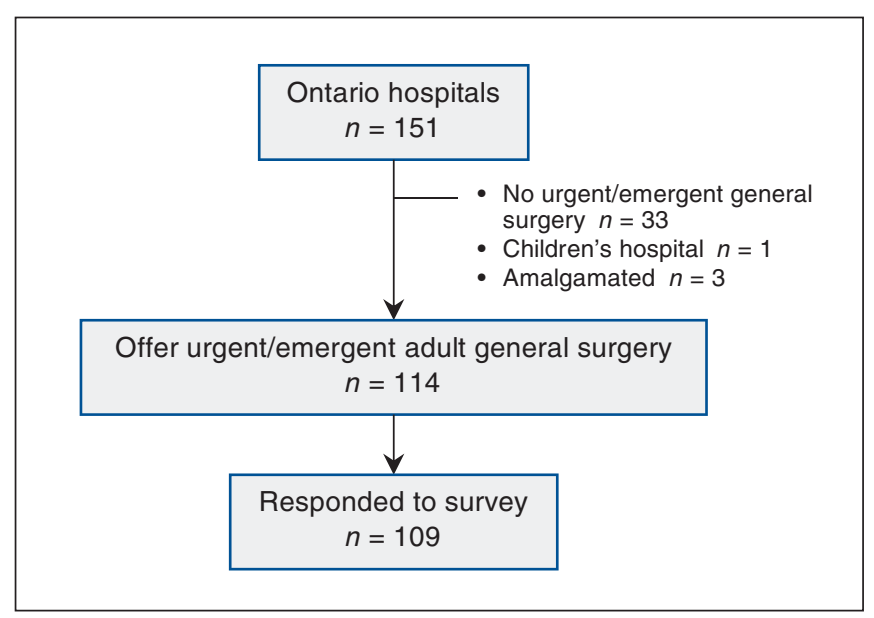

Figure 1: Hospital identification and study enrolment.

\section{Organizational structure and staffing}

One-third (34.6\%; $n=37 / 107)$ of Ontario hospitals had EGS models of care ( 2 hospitals did not answer this question). EGS models were most common among large (> 100-bed) academic hospitals $(83.3 \% ; n=15 / 18)$, followed by large nonacademic hospitals ( $41.3 \% ; n=19 / 46)$; they were uncommon in small (< 100-bed) nonacademic hospitals $(7.0 \% ; n=$ 3/43). Two hospitals had adopted EGS models of care in the 1980s, but all other institutions reporting a date of adoption for an EGS model of care had initiated EGS models after 2007; 12 of 37 (32.4\%) programs were initiated from 2016 to 2020 (Figure 2).

All general surgeons participated in the on-call schedule at $55.6 \%(n=40 / 72)$ of hospitals. Academic hospitals were less likely than nonacademic hospitals to have all surgeons take part in the on-call schedule $(35.2 \%[n=6 / 17]$ v. $61.8 \%[n=$ $34 / 55])$. Most hospitals with EGS models of care $(63.9 \%$ $[n=23 / 36])$ had all surgeons participate in the on-call schedule, compared to $47.2 \%(n=17 / 36)$ of hospitals without EGS models. Among hospitals with EGS models, 78.4\% $(n=$ 29/37) reported that more than three-quarters of surgeons participated in the on-call schedule. In hospitals without EGS models, only $37.5 \%(n=27 / 72)$ reported that more than three-quarters of surgeons participated in the on-call schedule. The likelihood that staff surgeons would have additional clinical responsibilities while on call (such as clinic or performing elective surgical or endoscopic procedures) was similar between hospitals with and without EGS models $(42.9 \%$ $[n=15 / 35]$ v. $52.6 \%[n=20 / 38])$.

Ontario hospitals with EGS models of care were more likely to have clinical associates $(20.0 \%[n=7 / 35]$ v. $4.9 \%[n=2 / 41])$, residents or fellows $(74.3 \%[n=26 / 35]$ v. $22.7 \%[n=10 / 44])$ and nurse practitioners or physician assistants $(36.1 \%[n=$ 13/36] v. $6.8 \%$ [ $n=3 / 44])$. Among large academic hospitals,

\begin{tabular}{|c|c|c|c|}
\hline \multirow[b]{2}{*}{ Respondent characteristic } & \multicolumn{3}{|c|}{ No. $(\%)$ of respondents } \\
\hline & $\begin{array}{l}\text { Large academic } \\
\quad n=18\end{array}$ & $\begin{array}{l}\text { Large nonacademic } \\
\qquad n=47\end{array}$ & $\begin{array}{l}\text { Small nonacademic } \\
\qquad n=44\end{array}$ \\
\hline \multicolumn{4}{|l|}{ Respondent role } \\
\hline Chair of emergency general surgery & $1(5.6)$ & $0(0)$ & $0(0)$ \\
\hline Chair of general surgery division & $10(55.6)$ & $7(14.9)$ & $0(0)$ \\
\hline General surgeon $\dagger$ & $4(22.2)$ & $15(31.9)$ & $1(2.3)$ \\
\hline Chief of surgery & $3(16.7)$ & $3(6.4)$ & $3(6.8)$ \\
\hline Chief of staff & $0(0)$ & $18(38.3)$ & $21(47.7)$ \\
\hline Manager of perioperative services (or equivalent) & $0(0)$ & $4(8.5)$ & $19(43.2)$ \\
\hline \multicolumn{4}{|l|}{ Respondent gender (self-reported) } \\
\hline Male & $11(61.1)$ & $26(55.3)$ & $21(47.7)$ \\
\hline Female & $7(38.9)$ & $21(44.7)$ & $23(52.3)$ \\
\hline \multicolumn{4}{|c|}{$\begin{array}{l}\text { *Hospitals were categorized as large academic hospitals with more than } 100 \text { beds that the Ministry of Health classifies as teaching hospitals, large } \\
\text { nonacademic hospitals with more than } 100 \text { beds that the Ministry does not classify as teaching hospitals, or small nonacademic hospitals with fewer } \\
\text { than } 100 \text { beds that the Ministry does not classify as teaching hospitals. } \\
\text { †Participation in the emergency general surgery on-call schedule. }\end{array}$} \\
\hline
\end{tabular}




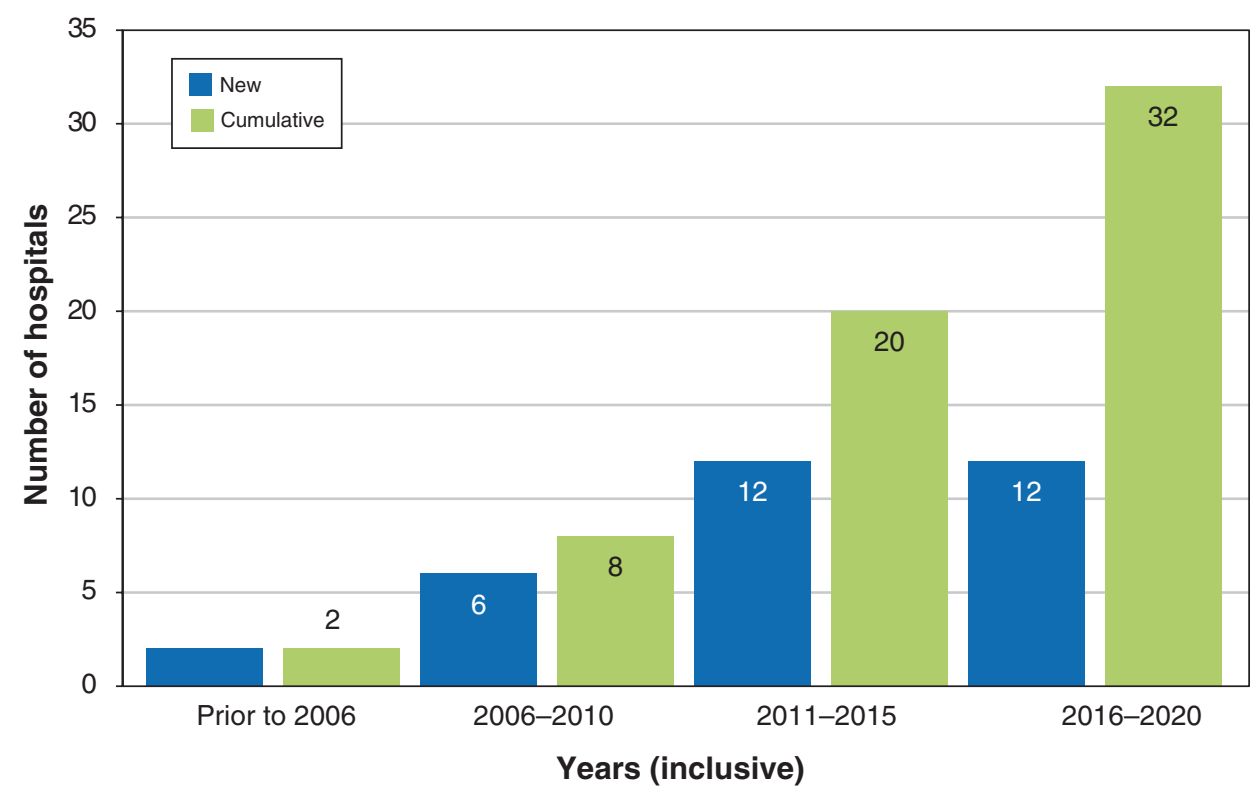

Figure 2: Date of adoption of an emergency general surgery model. Emergency general surgery models in Ontario have been adopted increasingly over time. Newly established emergency general surgery programs (blue) have been counted and plotted for each time period. The cumulative total of Ontario hospitals with an emergency general surgery program (green) has been calculated for the end date of each time period.

clinical associates, residents, fellows, nurse practitioners and physician assistants were seen exclusively at hospitals with EGS models of care. Of the hospitals with EGS models, 38.9\% ( $n=$ 14/36) had dedicated outpatient EGS clinics, compared to $2.3 \%(n=1 / 44)$ of hospitals without an EGS model (Table 2$)$.

\section{Operating room availability}

Access to the operating room at any time of day was available at $75.4 \%(n=77 / 102)$ of Ontario hospitals and was more common in hospitals with EGS models of care than in hospitals without $(94.4 \%[n=34 / 36]$ v. $65.1 \%[n=43 / 66])$. Only $23.5 \%(n=23 / 98)$ of hospitals provided dedicated operating room time for patients requiring EGS, all of which had adopted EGS models of care. Academic hospitals (58.8\%; $n=$ 10/17) were more likely to grant this dedicated time than nonacademic hospitals $(18.3 \% ; n=13 / 71)$. Of the large hospitals, 38.3\% $(n=23 / 60)$ had dedicated operating room time, but none of the small hospitals did.

Eighteen respondents ( 8 from academic hospitals, 10 from nonacademic hospitals) provided the exact number of operating room hours allotted to EGS each week. We found that academic hospitals provided more time (median $19.3 \mathrm{~h}, \mathrm{IQR}$ 9.8-28.7 h) than nonacademic hospitals (median $13.5 \mathrm{~h}$, IQR 9.5-17.5 h; Figure 3).

\section{Interventional radiology and interventional endoscopy availability}

Larger hospitals and academic hospitals had more access to computed tomography scanners, interventional radiology, endoscopy and endoscopic retrograde cholangiopancreatography (Table 2).
However, hospitals with EGS models of care had more access to these resources, even when we compared hospitals of similar size and academic status. Among large academic and large nonacademic hospitals, those with EGS models had more access to computed tomography scanners, interventional radiology, endoscopy and endoscopic retrograde cholangiopancreatography; small nonacademic hospitals had similar levels of access to these resources, regardless of whether or not they used EGS models of care (Table 2).

\section{Intensive care unit availability and staffing}

Large hospitals had more critical care resources (such as intensive care units, step-down units and critical care outreach teams) than small hospitals. At large academic and nonacademic hospitals, intensive care unit resources were similar whether the hospitals had EGS models of care or not. Among small, nonacademic hospitals, those with EGS models of care were more likely to have intensive care step-down units than those without $(66.7 \%[n=2 / 3]$ v. $18.9 \%[n=7 / 37])$, but the presence of outreach teams did not differ (Table 2).

\section{Regional participation}

Most Ontario hospitals had formal agreements allowing them to transfer patients to higher levels of care $(59.5 \% ; n=59 / 99)$ and accept transfers of patients requiring EGS $(62.6 \% ; n=$ 62/99). Small hospitals were more likely to have transfer agreements for patients requiring EGS than large hospitals $(85.0 \%[n=34 / 40]$ v. $40.1 \%[n=25 / 61])$. Among hospitals with EGS models of care, $31.4 \%(n=11 / 35)$ had formal agreements to transfer EGS patients out, compared to $75.0 \%$ 


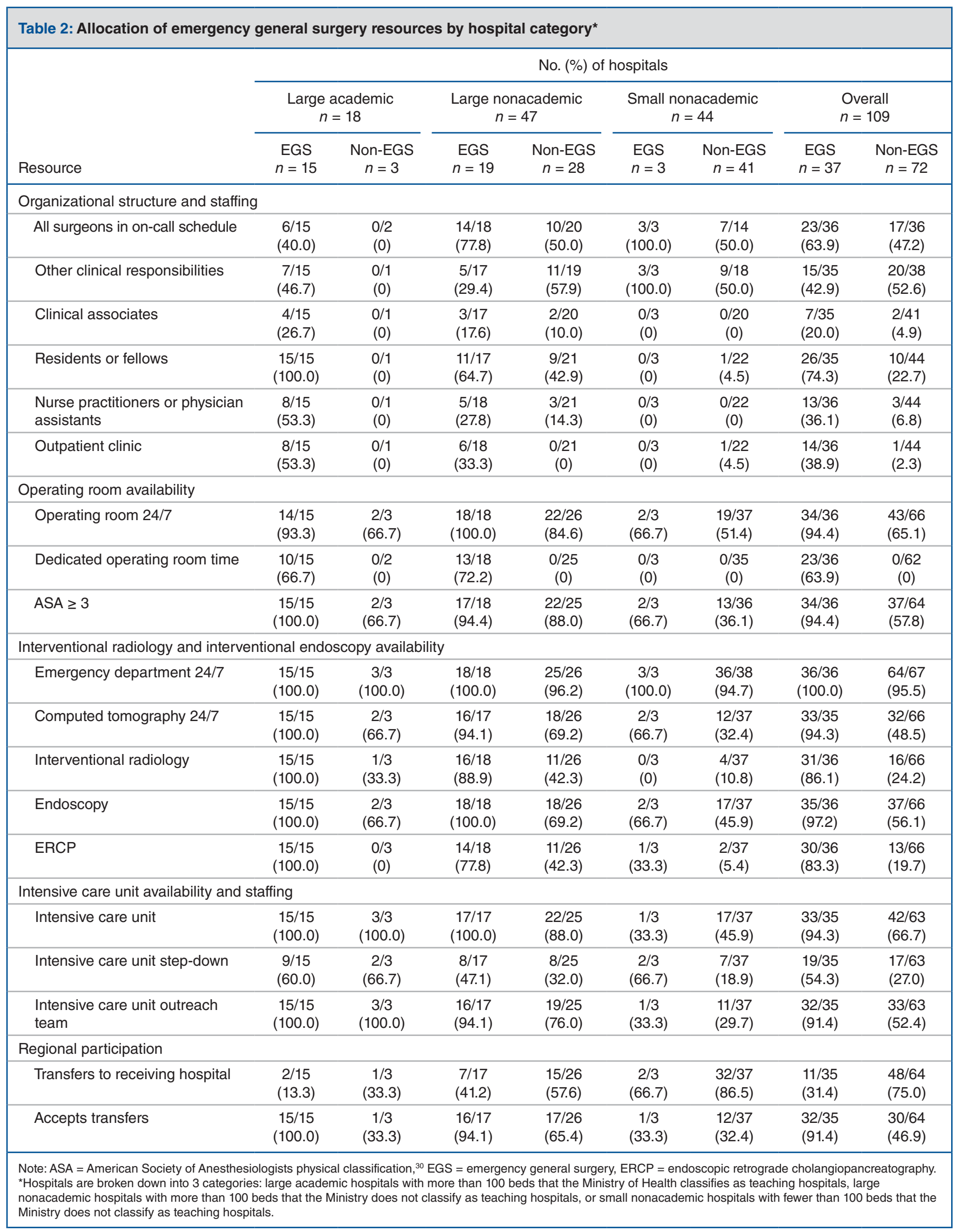




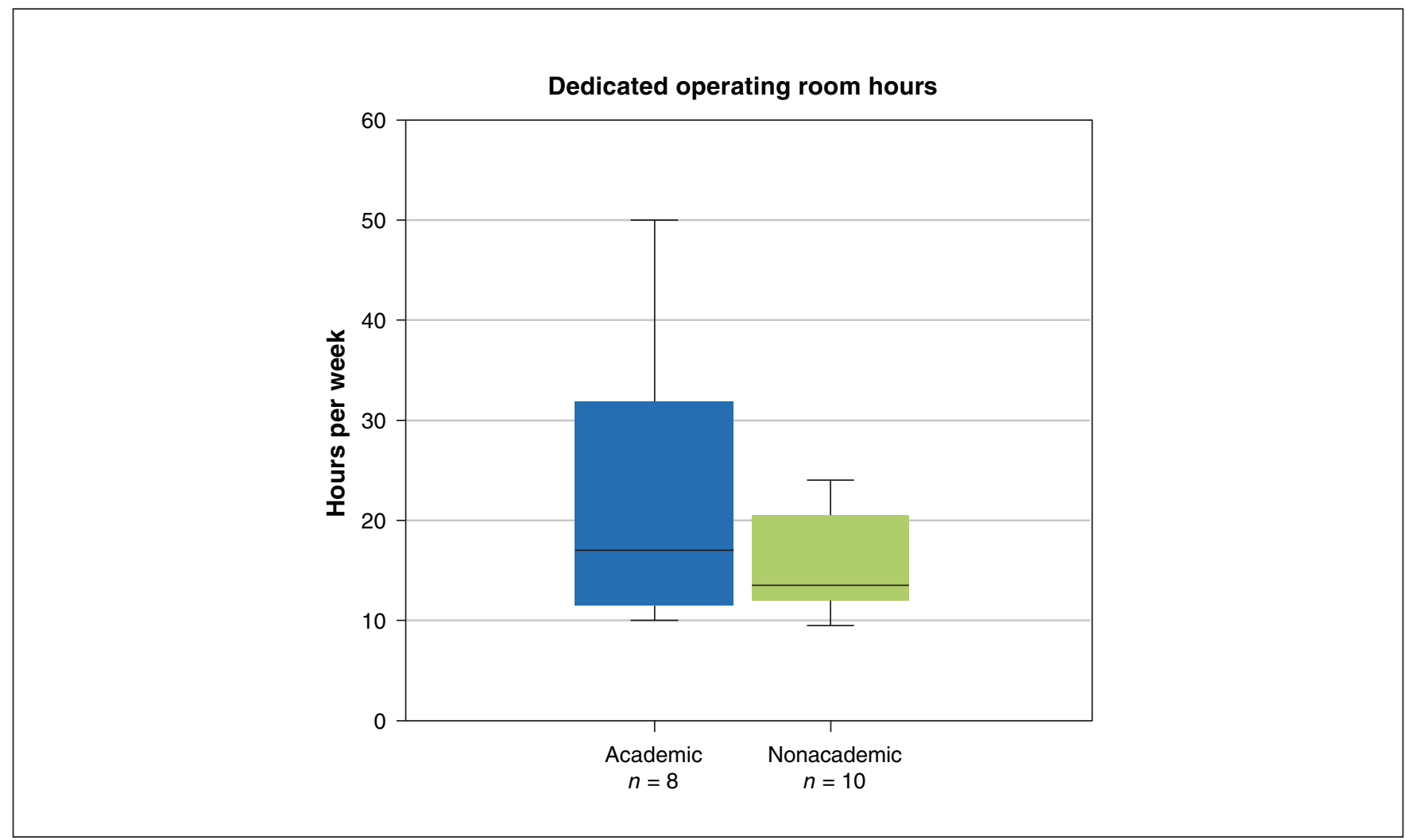

Figure 3: Dedicated operating room time for emergency general surgery. Eighteen respondents reported the number of operating room hours they provide each week for emergency general surgery. Findings are displayed for academic hospitals (those classified as teaching hospitals by the Ministry of Health) and nonacademic hospitals (those not classified as teaching hospitals by the Ministry of Health). Academic hospitals provided an average of 22.4 hours per week of operating room time; nonacademic hospitals provided an average of 15.6 hours per week. The middle line represents the median, and the boxplot represents the interquartile range.

$(n=48 / 64)$ of hospitals without EGS models. Similarly, 91.4\% $(n=32 / 35)$ of hospitals with EGS models had formal agreements to accept transfer of care for patients requiring EGS; only $46.9 \%(n=30 / 64)$ of hospitals without EGS models had such agreements in place (Table 2).

\section{Interpretation}

Our study characterized the structures and processes available for patients requiring EGS across Ontario. A third of hospitals had adopted EGS models of care, nearly half of those between 2016 and 2020 .

The benefits to patients of EGS models of care are emerging in the literature. Several studies have demonstrated significant reductions in morbidity and mortality, $7,13,14,31,32$ as well as improvements in wait times, length of stay and cost. ${ }^{13,15-17,33}$ Other specific hospital structures and processes (such as interventional radiology and endoscopy) play an important role in the management of patients requiring EGS; primary examples would be percutaneous drainage of intra-abdominal abscesses for complicated appendicitis or diverticulitis, and cholecystostomy tubes in those unable to tolerate surgery. ${ }^{34-36}$ In many cases, interventional radiology management is the definitive treatment under the guidance of general surgeons.
In Ontario hospitals, we found that EGS models of care are more common among large academic institutions, which have substantially more access to dedicated personnel, dedicated operating room time, diagnostic and therapeutic adjuncts and critical care resources. However, even when we compared large academic and nonacademic hospitals, we found that those with EGS models of care were more likely to have implemented key structures and processes.

The organization of EGS care in Canada is decades behind care for other acute conditions, such as trauma and stroke. In stark contrast to the care of injured patients - which has undergone decades of rigorous research, protocol standardization and regionalization at the prehospital, hospital and regional levels ${ }^{37,38,39}$ - current EGS models of care have been established ad hoc at most hospitals and care is dictated largely by the on-call general surgeon.

Patients requiring EGS receive care based on geographic proximity to a hospital, not on patient or disease factors, or on the capabilities of the closest hospital. This is concerning given that (as in other surgical disciplines) a volume-outcome relationship exists in EGS care. ${ }^{38,39}$ Risk-adjusted mortality decreases as volume increases for each of the 10 most common surgical procedures performed on patients requiring EGS, ${ }^{27}$ and there may be an institutional minimum annual volume of EGS cases below which mortality increases. ${ }^{28}$ 
These discrepancies are especially pronounced among older patients, who face an $86 \%$ higher risk of death when treated by low-volume surgeons. ${ }^{40}$ Some hospitals may best serve a subset of complex EGS patients (such as older patients or those with medical comorbidities) by engaging in robust transfer agreements with high-volume EGS centres.

Our study indicated that hospitals in Ontario providing care to patients requiring EGS did so in very different ways, similar to patterns seen in other geographic locations. ${ }^{11,22,41-43}$ This survey will be the foundation for population-based work that will attempt to identify which structures and processes of care are associated with improved outcomes. This database of EGS-specific structures and processes will be linked at ICES (www.ices.on.ca) to evaluate the association between EGS models of care and their components and the outcomes of patients with EGS conditions at a population-based level.

\section{Limitations}

We designed our survey to investigate the critical aspects of EGS care that others have identified and that (in our experience) affect the care of patients requiring EGS. It is likely that other important differences exist between EGS services that also play a role in EGS patient outcomes. Furthermore, this study relied on information gathered from a single person at each institution. We did not collect detailed demographic information about these people. If we had surveyed multiple people at the same institution, some answers may have varied. We made a substantial effort to identify ideal respondents with in-depth knowledge of their hospital's EGS program, but it is possible that some respondents were not certain of all answers. The survey took place over nearly 1 year, and some hospitals may have adjusted their EGS care models in that time.

\section{Conclusion}

The structures and processes relevant to the care of EGS patients are highly variable between hospitals. Regardless of academic status or hospital size, Ontario hospitals with EGS models of care had more access to many important EGS resources, including personnel, dedicated operating room time, and diagnostic and therapeutic adjuncts.

\section{References}

1. Hameed SM, Brenneman FD, Ball CG, et al. General surgery 2.0: the emergence of acute care surgery in Canada. Can 7 Surg 2010;53:79-83.

2. Gale SC, Shafi S, Dombrovskiy VY, et al. The public health burden of emergency general surgery in the United States: a 10-year analysis of the Nationwide Inpatient Sample-2001 to 2010. 7 Trauma Acute Care Surg 2014; 77:202-8.

3. DeGirolamo K, D'Souza K, Apte S, et al. A day in the life of emergency general surgery in Canada: a multicentre observational study. Can $\mathscr{f}$ Surg 2018;61:13517.

4. Ingraham AM, Cohen ME, Bilimoria KY, et al. Comparison of 30-day outcomes after emergency general surgery procedures: potential for targeted improvement. Surgery 2010;148:217-38.

5. Ingraham $\mathrm{AM}$, Cohen $\mathrm{ME}$, Raval MV, et al. Comparison of hospital performance in emergency versus elective general surgery operations at 198 hospitals. 7 Am Coll Surg 2011;212:20-8.e1.

6. Havens JM, Peetz AB, Do WS, et al. The excess morbidity and mortality of emergency general surgery. $\mathcal{F}$ Trauma Acute Care Surg 2015;78:306-11.

7. To KB, Kamdar NS, Patil P, et al. Acute care surgery model and outcomes in emergency general surgery. 7 Am Coll Surg 2019;228:21-8.e7.

8. Polk HC Jr, Bland KI, Ellison EC, et al. A proposal for enhancing the general surgical workforce and access to surgical care. Ann Surg 2012;255:611-7.
9. Ball CG, Hameed SM, Brenneman FD. Acute care surgery: a new strategy for the general surgery patients left behind. Can 7 Surg 2010;53:84-5.

10. Becher RD, Hoth JJ, Miller PR, et al. A critical assessment of outcomes in emergency versus nonemergency general surgery using the American College of Surgeons National Surgical Quality Improvement Program database. Am Surg 2011;77:951-9.

11. Santry HP, Madore JC, Collins CE, et al. Variations in the implementation of acute care surgery: results of a national survey of university-affiliated hospitals. 7 Trauma Acute Care Surg 2015;78:60-7, discussion 67-8.

12. Shafi S, Aboutanos MB, Agarwal S Jr, et al.; AAST Committee on Severity Assessment and Patient Outcomes. Emergency general surgery: definition and estimated burden of disease. 7 Trauma Acute Care Surg 2013;74:1092-7.

13. Cubas RF, Gómez NR, Rodriguez S, et al. Outcomes in the management of appendicitis and cholecystitis in the setting of a new acute care surgery service model: impact on timing and cost. 7 Am Coll Surg 2012;215:715-21.

14. Lehane CW, Jootun RN, Bennett $M$, et al. Does an acute care surgical model improve the management and outcome of acute cholecystitis? ANZ 7 Surg 2010;80:438-42.

15. Pepingco L, Eslick GD, Cox MR. The acute surgical unit as a novel model of care for patients presenting with acute cholecystitis. Med f Aust 2012;196:509-10.

16. Ogola GO, Haider A, Shafi S, et al. Hospitals with higher volumes of emergency general surgery patients achieve lower mortality rates: a case for establishing designated centers for emergency general surgery. 7 Trauma Acute Care Surg 2017;82:497-504.

17. Sorelli PG, El-Masry NS, Dawson PM, et al. The dedicated emergency surgeon: towards consultant-based acute surgical admissions. Ann R Coll Surg Engl 2008;90:104-8.

18. Suen K, Hayes IP, Thomson BNJ, et al. Effect of the introduction of an emergency general surgery service on outcomes from appendicectomy. $\mathrm{Br} \mathcal{F}$ Surg 2014;101:e141-6.

19. Anantha RV, Parry N, Vogt K, et al. Implementation of an acute care emergency surgical service: a cost analysis from the surgeons' perspective. Can $\mathrm{f}$ Surg 2014;57:E9-14.

20. Britt RC, Weireter LJ, Britt LD. Initial implementation of an acute care surgery model: implications for timeliness of care. 7 Am Coll Surg 2009;209:421-4.

21. Khalil M, Pandit V, Rhee P, et al. Certified acute care surgery programs improve outcomes in patients undergoing emergency surgery: a nationwide analysis. 7 Trauma Acute Care Surg 2015;79:60-3, discussion 64.

22. Schuster KM, McGillicuddy EA, Maung AA, et al. Can acute care surgeons perform emergency colorectal procedures with good outcomes? 7 Trauma 2011;71:94-100, discussion 100-1.

23. Hospital locations and classifications. Toronto: Ontario Ministry of Health and Ministry of Long-Term Care. Available: https://www.health.gov.on.ca/en/ common/system/services/hosp/hospcode.aspx (accessed 2019 Aug. 1).

24. R.R.O. 1990, Reg. 964: classification of hospitals. Public Hospitals Act, R.S.O 1990 Available: https://www.ontario.ca/laws/regulation/900964 (accessed 2021 Nov. 5).

25. Chana P, Burns EM, Arora S, et al. A systematic review of the impact of dedicated emergency surgical services on patient outcomes. Ann Surg 2016; 263:20-7.

26. Begg CB, Cramer LD, Hoskins WJ, et al. Impact of hospital volume on operative mortality for major cancer surgery. FAMA 1998;280:1747-51.

27. Becher RD, DeWane MP, Sukumar N, et al. Hospital volume and operative mortality for general surgery operations performed emergently in adults. Ann Surg 2020;272:288-303.

28. Ogola GO, Haider A, Shafi S. Hospitals with higher volumes of emergency general surgery patients achieve lower mortality rates: a case for establishing designated centers for emergency general surgery. 7 Trauma Acute Care Surg 2017;82:497-504.

29. Hoddinott SN, Bass MJ. The Dillman total design survey method. Can Fam Physician 1986;32:2366-8.

30. Saklad M. Grading of patients for surgical procedures. Anesthesiology $1941 ; 2: 281-4$.

31. Gandy RC, Truskett PG, Wong SW, et al. Outcomes of appendicectomy in an acute care surgery model. Med F Aust 2010;193:281-4.

32. Lau B, DiFronzo LA. An acute care surgery model improves timeliness of care and reduces hospital stay for patients with acute cholecystitis. Am Surg 2011;77:1318-21.

33. Ogola GO, Gale SC, Haider A, et al. The financial burden of emergency general surgery: national estimates 2010 to 2060. 7 Trauma Acute Care Surg 2015;79:444-8.

34. Park J, Charles H. Intra-abdominal abscess drainage: interval to surgery. Semin Intervent Radiol 2012;29:311-3.

35. Singh B, May K, Coltart I, et al. The long-term results of percutaneous drainage of diverticular abscess. Ann R Coll Surg Engl 2008;90:297-301.

36. Zarour S, Imam A, Kouniavsky G, et al. Percutaneous cholecystostomy in the management of high-risk patients presenting with acute cholecystitis: timing and outcome at a single institution. Am 7 Surg 2017;214:456-61.

37. Utter GH, Maier RV, Rivara FP, et al. Inclusive trauma systems: do they improve triage or outcomes of the severely injured? 7 Trauma 2006;60:529-35, discussion 535-7.

38. Nathens AB, Jurkovich GJ, Cummings $P$, et al. The effect of organized systems of trauma care on motor vehicle crash mortality. FAMA 2000;283:1990-4. 
39. Gomez D, Alali AS, Haas B, et al. Temporal trends and differences in mortality at trauma centres across Ontario from 2005 to 2011: a retrospective cohort study. CMA7 Open 2014;2:E176-82.

40. Mehta A, Dultz LA, Joseph B, et al. Emergency general surgery in geriatric patients: a statewide analysis of surgeon and hospital volume with outcomes. 7 Trauma Acute Care Surg 2018;84:864-75.

41. Committee to Develop the Reorganized Specialty of Trauma, Surgical Critical Care, and Emergency Surgery. Acute care surgery: trauma, critical care, and emergency surgery. $\mathcal{F}$ Trauma 2005;58:614-6.

42. Daniel V'T, Ingraham AM, Khubchandani JA, et al. Variation in the delivery of emergency general surgery care in the era of acute care surgery. $7 t \operatorname{Comm} 7$ Qual Patient Saf 2019;45:14-23.

43. Pottenger BC, Galante JM, Wisner DH. The modern acute care surgeon: characterization of an evolving surgical niche. 7 Trauma Acute Care Surg 2015;78:120-5.

Affiliations: Division of General Surgery (Skelhorne-Gross, Gomez), Department of Surgery, University of Toronto, Toronto, Ont.; Division of General Surgery (Nenshi), Department of Surgery, McMaster University, Hamilton, Ont.; Department of Anesthesia and Pain Medicine (Jerath), University of Toronto; Li Ka Shing Knowledge Institute (Gomez), St. Michael's Hospital; ICES Central (Jerath), Toronto, Ont.

Contributors: David Gomez conceived of the study, performed identification of hospitals and assisted with recruitment, survey design and editing and writing of the manuscript. Graham Skelhorne-Gross assisted with survey design, implemented the study, tabulated and analyzed data and was primary author of the study. Angela Jerath and Rahima Nenshi assisted with survey design, recruitment and editing and writing of the manuscript. All authors approved the final version to be published and agree to be accountable for all aspects of the work.

Content licence: This is an Open Access article distributed in accordance with the terms of the Creative Commons Attribution (CC BY-NC-ND 4.0) licence, which permits use, distribution and reproduction in any medium, provided that the original publication is properly cited, the use is noncommercial (i.e., research or educational use), and no modifications or adaptations are made. See: https://creativecommons.org/licenses/by-nc-nd/4.0/

Data sharing: The dataset is not available for data sharing at the facility level without modification to the associated research ethics board application and will be considered only in special circumstances.

Supplemental information: For reviewer comments and the original submission of this manuscript, please see www.cmajopen.ca/content/9/4/ E1026/suppl/DC1

ICES disclaimer: This study was supported by ICES, which is funded by an annual grant from the Ontario Ministry of Health $(\mathrm{MOH})$. The opinions, results and conclusions reported in this article are those of the authors and are independent from the funding sources. No endorsement by ICES or the Ontario MOH is intended or should be inferred. 